\title{
Sistema Santa Fé auxilia na redução do escoamento superficial e melhoria da qualidade da água?
}

Vanessa de Fátima Grah Ponciano ${ }^{1}$, Luanne Martins de Siqueira Gama ${ }^{1}$, Makcy Ramon Kened Sousa Silva ${ }^{1}$, Sihelio Julio Silva $\mathrm{Cruz}^{1}$, Isaac de Matos Ponciano ${ }^{2}$, Silvia Sanielle Costa de Oliveira ${ }^{1}$

${ }^{1}$ Instituto Federal Goiano - IF Goiano, GO. ${ }^{2}$ Faculdade de Iporá - FAl, GO. E-mail: vanessa.grah@ifgoiano.edu.br

\section{Resumo}

A cobertura vegetal na superfície do solo é uma prática fundamental para o estabelecimento de sistemas conservacionistas do solo e da água. O Sistema Santa Fé consiste na inclusão de espécies forrageiras no sistema de produção de grãos, sobretudo por consorciação. O objetivo do estudo foi avaliar o efeito do cultivo do milho solteiro e do milho em consórcio com capim U. brizantha cv. marandu, no escoamento superficial e qualidade da água escoada utilizando um simulador de chuvas. $O$ experimento foi realizado na Fazenda Escola do IF Goiano Campus Iporá em Neossolo Quartzarênico argiloso, em uma região do Cerrado. As seguintes coberturas do solo foram avaliadas: solo descoberto, milho híbrido solteiro e Sistema Santa Fé. Para a determinação do volume escoado e a qualidade da água escoada em cada tratamento foram realizados três testes, utilizando-se um simulador de chuvas pendular construído no IF Goiano Campus Iporá. Em cada teste foram contabilizadas o volume total de água escoada e a cada cinco minutos foram coletadas amostras para caracterização da qualidade da água, nas quais foram analisadas a turbidez, $\mathrm{pH}$ e condutividade elétrica. As perdas de água foram reduzidas $82 \%$ e a turbidez em $96 \%$ no sistema Santa Fé, em comparação ao solo descoberto. O Sistema Santa Fé apresentou melhor desempenho com menor volume de escoamento superficial e melhor qualidade da água escoada quando avaliada a turbidez, o que demonstra o seu elevado potencial em minimizar a erosão hídrica do solo.

Palavras-chave: integração lavoura-pecuária; Cerrado; milho em consórcio; simulador de chuvas.

\section{Santa Fé System assists in reducing runoff and improvement the quality of water?}

\begin{abstract}
The cover crop on the soil surface is a fundamental practice for the establishment of soil and water conservation systems. The Santa Fé System consists of the inclusion of forage species in the grain production system, mainly by intercropping. The objective of the study was to evaluate the effect of cultivation of single maize and maize in consortium with $\mathrm{U}$. brizantha $\mathrm{cv}$. marandu, in runoff and quality of runoff using a rainfall simulator. The experiment was carried out at the School Farm of the IF Goiano Campus Iporá in a Quartzipsament, in a Brazilian Savanna region. The following land cover were evaluated: uncovered soil, single hybrid corn and Santa Fé System. For the determination of the runoff volume and the runoff quality, three tests were performed in each treatment, using a pendulum rainfall simulator built at the IF Goiano Campus Iporá. In each test, the total volume of runoff was counted and every five minutes samples were collected to characterize the runoff quality, in which turbidity, $\mathrm{pH}$ and electrical conductivity were analyzed. Water losses were reduced by $82 \%$ and turbidity by $96 \%$ in the Santa Fé system, compared to uncovered soil. The Santa Fé System showed better performance with less runoff volume and better quality of runoff when turbidity was evaluated, which demonstrates its high potential in minimizing soil water erosion.
\end{abstract}

Keywords: crop-livestock systems; Brazilian Savanna; maize in intercropping; rainfall simulator. 


\section{Introdução}

A erosão hídrica é um processo natural que consiste na desagregação, transporte e deposição das partículas do solo; todavia, pode ser intensificada pela falta de sistemas conservacionistas. Em tais locais podem ocorrer contaminação e poluição dos rios por dejetos animais e fertilizantes químicos (LEMOS et al., 2020), bem como perdas de nutrientes do solo (ARAUJO et al., 2016), com consequências ambientais e socioeconômicas relevantes (DECHEN et al., 2015). A disposição da cobertura vegetal na superfície do solo é uma prática fundamental para o estabelecimento de sistemas conservacionistas do solo e da água.

Com a introdução da cobertura vegetal obtêm-se a melhoria nos atributos físicos e químicos do solo, na ciclagem dos nutrientes, incremento de matéria orgânica ao solo, redução da velocidade do escoamento superficial, rompimento de camadas compactadas, aumento da atividade biológica do solo (SANTOS et al., 2014; FINNEY; KAYE, 2017), ajuda a manter a umidade do solo (LIMA et al., 2020), o que possibilita um melhor desempenho das culturas e redução da frequência de irrigação (CAMPIGLIA et al., 2010).

Além destes benefícios a conservação dos resíduos vegetais na superfície do solo pode interceptar as gotas de chuva, diminuindo o impacto e evitando a desagregação de partículas (DECHEN et al., 2015). Assim, sistemas conservacionistas que promovam pequena ou nenhuma movimentação mecânica do solo, que mantém grande parte dos resíduos das culturas sobre o solo e que eleva a rugosidade superficial são mais eficientes no que se refere ao controle das perdas de solo e água por erosão hídrica (ZANGISKI et al., 2018). Nesse sentido, algumas pesquisas têm sido realizadas com o objetivo de avaliar como as diferentes formas de manejo têm influenciado no processo de perda de solo e de água (PANACHUKI et al., 2011; PRAZERES et al., 2020; BRAMORSKI; CRESTANA, 2020).

Gramíneas farrageiras podem ser utilizadas tanto para fornecimento de alimento aos animais, como para a proteção do solo. Dessa forma, gramíneas forrageiras em consórcio as culturas comerciais promovem a manutenção da cobertura vegetal e raízes. Diversos aspectos são considerados quanto as características das gramíneas forrageiras como, elevada produção de fitomassa (MELO et al., 2017) e sistema radicular com alta densidade de raízes, o que promove a aproximação das partículas de solo pela constante absorção da água (BERNATEKJAKIEL et al., 2017). Além disso, geralmente apresentam elevada relação Carbono/Nitrogênio devido ao grande potencial de manutenção da palha sobre o solo, retardando a decomposição, o que possibilita sua utilização em regiões quentes, como o Cerrado (PARIZ et al., 2011; FINNEY; KAYE, 2017).

É imprescindível a necessidade de se inserir nas propriedades rurais práticas agrícolas que, ao mesmo tempo, promovam a conservação e a utilização dos serviços dos ecossistemas para o desenvolvimento sustentável da agricultura. Neste sentido, as gramíneas forrageiras vêm apresentando melhor desempenho em sistemas com plantio direto, integração lavoura pecuária ou sistema santa fé, principalmente as do gênero Urochloa (PARIZ et al., 2011, NEVES et al., 2018; GLÉRIA et al., 2017).

O Sistema Santa Fé consiste na inclusão de espécies forrageiras no sistema de produção de grãos, sobretudo por consorciação. Esse sistema apresenta como vantagens a produção de grãos e disposição de palha de qualidade para o sistema de plantio direto ou recuperação de pastagens (KLUTHCOUSKI; AIDAR, 2003). Dentre as diversas opções de capins utilizados para pastagens, as cultivares de Urochloa brizantha (Xaraés e Marandu) apresentam boa adaptação e produção de forragem em solos de média fertilidade natural (MEDICA et al., 2017). Principalmente por seus resíduos promoverem a melhoria do solo através da estruturação e a estabilidade dos agregados decorrentes da alta densidade de raízes (MELO et al., 2017).

Nesse sentido, o uso do consórcio de milho com capim-marandu (Sistema Santa Fé) pode reduzir o escoamento superficial e melhorar a qualidade da água escoada quanto aos parâmetros físico-químicos, como $\mathrm{pH}$, turbidez e condutividade elétrica. $\mathrm{O}$ objetivo do estudo foi avaliar o efeito do cultivo do milho solteiro e do milho em consórcio com capim U. brizantha cV. marandu, no escoamento superficial e qualidade da água escoada utilizando um simulador de chuvas.

\section{Material e métodos \\ Local e Tratamento Experimental}

O experimento foi realizado na Fazenda

Escola do Instituto Federal Goiano - Campus Iporá no estado de Goiás $\left(16^{\circ} 25^{\prime} 23.6^{\prime \prime} \mathrm{S}\right.$ $\left.51^{\circ} 08^{\prime} 59.6 " \mathrm{~W}\right)$. O clima é do tipo Aw de acordo 
com a classificação de Köppen, com uma precipitação média anual de $1.613 \mathrm{~mm}$. O solo da área foi classificado como um Neossolo Quartzarênico argiloso, de acordo com EMPRAPA (2018). A distribuição da precipitação anual na região é concentrada nos meses de outubro a maio, com um período de seca bem definido entre os meses de junho a setembro.

O solo da área experimental foi preparado de forma convencional com aração e gradagem, na segunda quinzena de novembro de 2019, ou seja, a cultura se desenvou na época chuvosa. Contudo, os testes de chuva simulada foram realizados no início da estação seca. $\mathrm{Na}$ área de estudo, instalaram-se três parcelas com diferentes coberturas vegetais, cada uma com área igual a $32 \mathrm{~m}^{2}(2,0 \times 16,0 \mathrm{~m})$, com a menor dimensão da parcela na direção da inclinação do solo de $1,2 \%$. Aplicaram-se os seguintes tratamentos:

- T1: Sistema Santa Fé, com milho híbrido (Brevant Sementes, B2 620 PWU) em consórcio com capim-marandu (Urochloa brizantha cv. Marandu), com uma população de 60000 plantas ha ${ }^{-1}$ de milho e o capim-marandu semeado a lanço após o planto do milho em uma quantidade de $10 \mathrm{~kg} \mathrm{ha}^{-1}$;

- T2: milho híbrido solteiro (Brevant Sementes, B2 620 PWU), com uma população de 60000 plantas ha $^{-1}$;

- T3: solo descoberto.

A área total do experimento compreendia $96 \mathrm{~m}^{2}$ (6,0 x 16,0 m). Foi utilizado o delineamento experimental em faixas. As faixas foram compostas pelos 3 tratamentos citados, portanto em uma faixa se aplicou o Sistema Santa Fé (T1), outra faixa com Milho Hídrido Solteiro (T2) e, por fim a última faixa com Solo descoberto (T3). Empregaram-se 3 blocos de forma que cada bloco continha os três tratamentos. O simulador de chuva foi aplicado 3 vez em cada faixa de tratamento dentro do bloco. Portanto, o experimento dispunha de 36 parcelas experimentais nas quais foi aplicado o simulador de chuva $\left(1 \mathrm{~m}^{2}\right)$.

\section{Tratos culturais e formação de biomassa de cobertura}

Os tratos culturais foram conduzidos de forma similar tanto para o milho solteiro quanto para o sistema Santa Fé, a saber: adubação de base com aplicação de $400 \mathrm{~kg} \mathrm{ha}^{-1}$, do formulado 08-28-16; adubação de cobertura de forma parcelada, nos estágios V4 e V8, com aplicação de $40 \mathrm{~kg} \mathrm{ha}^{-1}$ de ureia e $40 \mathrm{~kg} \mathrm{ha}^{-1}$ cloreto de potássio; o controle de pragas e doenças foi realizado com a aplicação de defensivos químicos recomendados para as principais pragas e doenças no manejo das culturas.

Quando as plantas de milho atingiram o estádio de maturação fisiológica dos grãos, realizou-se o corte das plantas de milho a $20 \mathrm{~cm}$ da superfície do solo, em seguida as plantas foram separadas das espigas e trituradas em picadeira de forragem. A biomassa picada foi distribuída uniformemente nas parcelas experimentais simulando a operação de colheita mecanizada.

\section{Simulador de chuva portátil pendular e coleta das amostras de escoamento superficial}

O simulador de chuva portátil utilizado no trabalho foi desenvolvido no Instituto Federal Goiano Campus Iporá, conforme os princípios de funcionamento dos simuladores descritos por Alves Sobrinho et al. (2002). Após 15 dias da colheita do milho, iniciou-se aos testes de escoamento superficial da água nos diferentes tratamentos, utilizando um simulador portátil pendular (FIGURA 1). A intensidade de precipitação média utilizada no simulador de chuva para todos os testes foi de $9,21 \mathrm{~mm} \mathrm{~min}^{-1}$, com um coeficiente de uniformidade estatístico (CUE) de $75 \%$. 
Figura 1. Simulador de chuvas pendular construído no IF Goiano Campus Iporá e utilizado para os testes de escoamento superficial e qualidade da água escoada em diferentes coberturas do solo para uma área de amostragem igual a $1 \mathrm{~m}^{2}$.

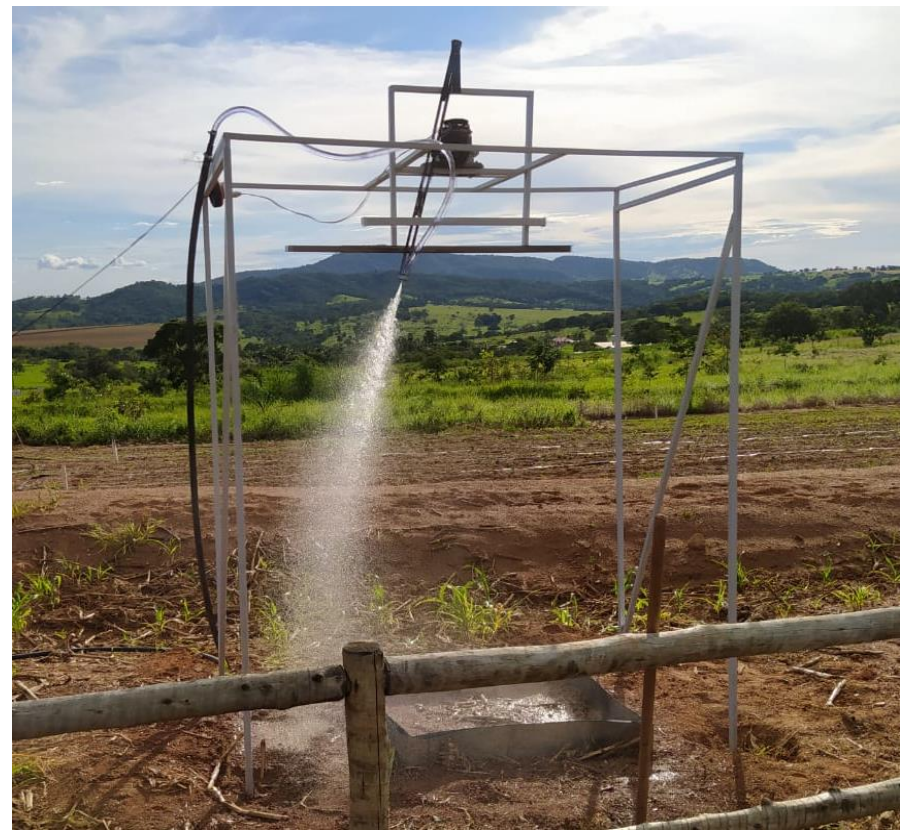

Antes de realizar os testes, na área específica para cada tratamento, foram coletadas três amostras de solo em três pontos aleatórios, na camada de $0-20 \mathrm{~cm}$, para determinação da umidade gravimétrica do solo por meio do método padrão da estufa (EMBRAPA, 1997).

Também foram coletadas amostras de cobertura vegetal para determinação da matéria seca dos restos vegetais. Dentro de cada tratamento foi delimitado uma área de $1 \mathrm{~m}^{2}$, onde toda a cobertura vegetal foi retirada (Sistema Santa Fé e milho híbrido solteiro), três repetições foram realizadas. As amostras foram pesadas e utilizadas para a retirada de sub amostras que foram novamente pesadas. No tratamento de milho solteiro foram coletados os restos culturais do milho, já no sistema Santa Fé foram coletados os restos do milho juntamente com o capim.

Para determinação do volume escoado e a qualidade da água foram feitos 3 testes em cada tratamento. Cada teste teve duração de 20 minutos, com o início do escoamento sendo o tempo zero, segundo metodologia descrita por Bertol et al. (2011). Para quantificicação do volume escoado, foi coletada toda água durante os 20 minutos. As amostras para se quantificar a qualidade da água foram realizadas a cada cinco minutos, cada volume amostrado foi dividido em três sub amostras para determinação da turbidez, $\mathrm{pH}$ e condutividade elétrica da água escoada. A primeira amostragem foi realizada no início do escoamento superficial da água na calha coletora (PANACHUKI et al., 2011). Após o início do escoamento superficial o teste teve duração de de 20 minutos, totalizando 12 amostras de água escoada, para cada parâmetro de qualidade da água. Para a determinação da qualidade água escoada as análises de turbidez, pH e condutividade elétrica foram realizadas em um turbidímetro de bancada (AP2000, PoliControl), phmetro de bancada (PHS-3E, Even) e um condutivímetro portátil, respectivamente. Todas as amostras foram analisadas nos Laboratórios das Ciências Agrárias do IF Goiano Campus Iporá.

Os resultados foram submetidos à análise de variância e as médias foram comparadas pelo teste Tukey, ao nível de $5 \%$ de probabilidade, utilizando o programa de análise estatística SISVAR (FERREIRA, 2014).

\section{Resultados e discussão}

A umidade do solo antes dos testes para - sistema Santa Fé, milho solteiro e solo descoberto foi de 12,4\%, 9,1\% e 10,9\%, respectivamente. Como o solo estudado é um Neossolo quartzarênico de textura argilosa, a capacidade de retenção de água é pequena, alcançando valores de umidade de $0,29 \mathrm{~cm}^{3} \mathrm{~cm}^{-3}$ no solo saturado e $0,19 \mathrm{~cm}^{3} \mathrm{~cm}^{-3}$ na umidade a capacidade de campo, na camada de $0-20 \mathrm{~cm}$ (valores extradídos da curva de retenção de umidade). Assim, com uma faixa de retenção de 
umidade mais baixa, a umidade antecedente do solo passa a não demonstrar grande influência na geração de escoamento superficial (LIMA et al., 2020). Em relação a cobertura vegetal, o milho solteiro teve uma cobertura, de aproximadamente, um quarto da cobertura do sistema Santa Fé, com valores médios de matéria seca (MS) igual a $0,041 \mathrm{Kg} \mathrm{m}^{-2}$ para o milho solteiro e 0,151 $\mathrm{Kg} \mathrm{m}^{-2}$ para o sistema Santa Fé.

Durante os testes as maiores perdas de volume de água escoada foram verificadas no solo descoberto (Tabela 1), sem nenhum tipo de cobertura vegetal. Já os tratamentos que apresentavam cobertura vegetal de milho solteiro e sistema Santa Fé não diferenciaram entre si, contudo, apresentaram diferença significativa quando comparados com o solo descoberto. Resultados semelhantes foram apresentados por Zolin et al. (2016), que comparando diferentes coberturas vegetais e usos do solo, obtiveram maiores perdas de água no solo descoberto.

Tabela 1. Volume médio resultante do escoamento superficial $(\mathrm{mm})$ para os tratamentos de solo descoberto, milho solteiro e sistema Santa Fé, sob precipitação simulada de 9,21 $\mathrm{mm} \mathrm{min}^{-1}$, com duração de 20 minutos

\begin{tabular}{cc}
\hline Tratamentos & Escoamento superficial (mm) \\
\hline Solo descoberto & $116,94 \mathrm{a}$ \\
Milho solteiro & $46,20 \mathrm{~b}$ \\
Milho consorciado & $20,64 \mathrm{~b}$ \\
\hline dia seguidas da mesma letra minúscula na coluna não diferem entre si, pelo teste de Tukey $(p=0,05)$.
\end{tabular}

A perda de água no solo descoberto resultou em uma média de $116,94 \mathrm{~mm}$, valor menor que o encontrado por Zolin et al. (2016) sob chuva natural. Mas, valor próximo ao apresentado por Silva et al. (2005), que ao analisarem as perdas de águas em um solo descoberto, utilizando-se um simulador de chuva com intensidade de precipitação de $120 \mathrm{~mm} \mathrm{~h}^{-1}$, obtiveram uma perda de 117, $3 \mathrm{~mm}$.

As perdas de água foram reduzidas em $60 \%$ no milho solteiro e, em $82 \%$ no sistema Santa Fé, em comparação ao solo descoberto. Zolin et al. (2016) apresentou, para um sistema de integração lavoura-floresta, uma redução de $91 \%$ na perda de água quando comparado com o solo descoberto. Silva et al. (2005) e Pires et al. (2006) também observaram reduções significativas de perdas de água, nos tratamentos que continham cobertura vegetal. Segundo Viel et al. (2017) a cobertura vegetal deve proteger o solo dos processos erosivos, sendo importante no equilíbrio e conservação do solo, ajudando na retenção de água no solo, redução da velocidade do escoamento e reduzindo as taxas de erosão. 0 milho consorciado com gramíneas (ILP) além de oferecer uma melhor proteção do solo pode ainda, gerar um nível ótimo de produção de biomassa, garantindo a cobertura do solo e não prejudicando o desenvolvimento da lavoura (CARVALHO et al., 2005).

Analisando as variáveis de qualidade da água escoada, para a turbidez foi observado que o sistema Santa Fé apresentou o menor valor. Para condutividade elétrica, os tratamentos com milho solteiro e sistema Santa Fé não diferenciaram entre si, contudo, apresentaram valores superiores ao solo descoberto. Para o pH o milho solteiro se diferenciou estatisticamente dos outros tratamentos e apresentou maior média (Tabela 2). 
Tabela 2. Valores médios das variáveis analisadas para qualidade da água escoada: turbidez (UNT), pH (potencial hidrogeniônico da água), condutividade elétrica $\left(\mu \mathrm{S} \mathrm{cm}^{-1}\right)$; para os tratamentos de solo descoberto, milho solteiro e sistema Santa Fé.

\begin{tabular}{cccc}
\hline Tratamentos & Turbidez & $\mathrm{pH}$ & Condutividade elétrica \\
\hline Solo descoberto & $711,92 \mathrm{a}$ & $8,69 \mathrm{~b}$ & $29,67 \mathrm{~b}$ \\
Milho solteiro & $149,80 \mathrm{~b}$ & $9,02 \mathrm{a}$ & $40,61 \mathrm{a}$ \\
Milho consorciado & $27,31 \mathrm{c}$ & $8,84 \mathrm{ab}$ & $44,83 \mathrm{a}$ \\
\hline
\end{tabular}

*média seguidas da mesma letra minúscula na coluna não diferem entre si, pelo teste de Tukey $(\alpha=0,05)$. UNT Unidade Nefelométrica de Turbidez.

A maior produção de biomassa, por parte do capim-marandu, ocasionou redução da velocidade das gotas da precipitação artificial produzida pelo simulador de chuvas. Por conseguinte, observou-se redução de $96 \%$ na turbidez quando comparado com 0 solo descoberto. Segundo Lima et al. (2020), os solos com vegetação mais desenvolvida diminuiem o impacto direto das gotas de chuva, protegendo o solo. Esse fenômeno associado a má infiltração de água e escoamento superficial facilitam o processo de transporte, contribuindo no aumento da turbidez da água (BERTOL et al., 1987; FACHIN et al., 2019; NACHTIGALL et al., 2020).

Já os tratamentos com milho solteiro e solo descoberto apresentaram, respectivamente, pouca $\left(0,041 \mathrm{Kg} \mathrm{m}^{-2}\right)$ e nenhuma cobertura de solo, fato que contribui para o maior carreamento de partículas e turbidez. Silva et al. (2005) testaram diferentes níveis de cobertura de solo e, concluíram que o solo com $100 \%$ de cobertura não apresentou perdas de partículas. Lima et al. (2020) ratificam que quando ocorre um grande volume de escoamento de água com elevado turbidez favorece-se perdas de solo e matéria orgânica, gerando problemas com erosões e deposição de sedimentos em águas receptoras.

Nota-se que a condutividade elétrica para o solo descoberto foi menor que para os solos com cobertura vegetal. Isso ocorreu, devido à ausência de aplicação de adubos no tratamento de solo descoberto. Já os tratamentos com o milho solteiro e sistema Santa Fé receberam três adubações ao longo do ciclo o que disponibilizou maior quantidade de sais nas camadas superficiais do solo. A condutividade elétrica permite avaliar o potencial que a água oferece em produzir danos, em termos de salinização do solo, sendo a variável mais empregada para se avaliar o nível de salinidade (FARZAMIAN et al., 2019). Adicionalmente, tal parâmetro pode servir para mensurar a quantidade de sais perdidos devido ao escoamento subsuperficial que, portanto, implica em ineficiência na aplicação de fertilizantes e aumento de custos de produção.

Lemos et al. (2020) não encontraram diferenças nos valores de condutividade elétrica na água de escoamento, ao se comparar diferentes sistemas de manejo do solo. Os autores apresentaram valores médios de condutividade elétrica de 43,78 e $44,51 \mu \mathrm{S} \mathrm{cm}$ ${ }^{1}$ para o sistema convencional e de plantio direto respectivamente, valores muito próximos dos resultados encontrados na cobertura com milho solteiro e sistema Santa Fé. Os valores encontrados estão dentro da faixa de valores comumente encontrados na água doce, a saber: de 5 a $50 \mu \mathrm{S} \mathrm{cm}^{-1}$ (MESTRINHO, 2013).

Ao confrontar os resultados de $\mathrm{pH}$ com os limites definidos na Resolução CONAMA no 357/2005 (BRASIL, 2005), constata-se que eles estão muito próximos do limite estabelecido pela referida resolução, entre 6 e 9, para águas doces de todas as classes. A água escoada em corpos hídricos com $\mathrm{pH}$ ácido se ingeridos constantemente, podem ser prejudiciais à saúde humana (MARQUES et al., 2020), adicionalmente a elevação do $\mathrm{pH}$ aumenta a concentração da forma não iônica da amônia, ou seja, a fração tóxica da amônia na água (LIMA, 2019). Em pH mais alcalino, acima de 7, ocorre maior transformação do íon amônio $\left(\mathrm{NH}^{4+}\right)$ em amônia livre e gasosa $\left(\mathrm{NH}^{3}\right)$, tóxica aos peixes (LIMA, 2019).

Lemos et al. (2020) ao analisar o pH na água de escoamento, comparando diferentes sistemas de manejo do solo, também não encontraram diferença significativa entre os 
tratamentos. Os autores apresentaram valores de $\mathrm{pH}$ de 6,56 e 6,66 em sistemas convencionais e de plantio direto, respectivamente, valores abaixo do encontrado para a cobertura vegetal de milho solteiro e sistema Santa Fé.

\section{Conclusão}

O sistema Santa Fé proporciona melhor desempenho com menor volume de escoamento superficial e melhor qualidade da água escoada quando avaliada a turbidez.

Em condições de intensidade de precipitação de $9,21 \mathrm{~mm} \mathrm{~min}^{-1}$ e tempo de duração de 20 minutos, o sistema Santa Fé apresentau ma redução de $82 \%$ no volume escoado e $96 \%$ na turbidez da água de escoamento, quando comparado com o solo descoberto.

\section{Agradecimentos}

Ao Instituto Federal Goiano por disponibilizar todo o suporte para realização do experimento e ao Grupo de pesquisa Cerrado Verde.

\section{Referências}

ALVES SOBRINHO, T.; FERREIRA, P. A.; PRUSKI, F. F. Desenvolvimento de um infiltrômetro de aspersão portátil. Revista Brasileira de Engenharia Agrícola e Ambiental, v. 6, n. 2, p. 337-344, 2002. https://doi.org/10.1590/S1415$\underline{43662002000200025}$

ARAUJO, Y. R.; SOUZA, C. A.; ARAÚJO NETO, J. R.; RIBEIRO FILHO, J. C.; LIMA, J. W. C. Perda de nutriente e custo da erosão em microbacia no semiárido brasileiro. Revista Geonorte, v. 7, n. 26 (Espec. n. 5), p. 206-219. 2016. https://www.periodicos.ufam.edu.br/index.php/r evista-geonorte/article/view/2768

BERNATEK-JAKIEL, A.; VANNOPPEN, W.; POESEN, J. Assessment of grass root effects on soil piping in sandy soils using the pinhole test. Geomorphology, v. 295, n. 1, p. 563-571, 2017. https://doi.org/10.1016/i.geomorph.2017.08.027

BERTOL, I.; COGO, N.P.; LEVIEN, R. Relações da erosão hídrica com métodos de preparo do solo, na ausência e na presença de cobertura por resíduo cultural de trigo. Revista Brasileira de Ciência do Solo, v. 11, p. 187-192, 1987. https://doi.org/10.1590/s0100$\underline{06831997000300009}$
BERTOL, O. J.; RIZZI, N. E.; FEY, E.; LANA, M. C. Perda de nutrientes via escoamento superficial no sistema plantio direto sob adubação mineral e orgânica. Ciência Rural, v. 41, n. 11, p. 19141920, 2011. https://doi.org/10.1590/S010384782011005000135

BRASIL. Resolução no 357/2005. Dispõe sobre a classificação dos corpos de águas e diretrizes ambientais para o seu enquadramento, bem como estabelece as condições padrões de lançamento de efluentes, promulgada em 17 de março de 2005. Diário Oficial da União, Brasília, 2005.

BRAMORSKI, J.; CRESTANA, S. Erosão hídrica em um Latossolo Vermelho-Amarelo sob diferentes sistemas de manejo e chuva simulada. Revista Sítio Novo Palmas, v. 4, n. 2, p. 73-80, 2020. https://doi.org/10.47236/2594-

7036.2020.v4.i2.73-80p

CAMPIGLIA, E.; MANCINELLI, R.; RADICETTI, E.; CAPORALI, F. Effect of cover crops and mulches on weed control and nitrogen fertilization in tomato (Lycopersicon esculentum Mill.). Crop Protection, v. 29, n. 4, p. 354-363, 2010. https://doi.org/10.1016/j.cropro.2009.12.001

CARVALHO, P. C. F.; ANGHINONI, I.; MORAES, A.; TREIN, C. R.; FLORES, J. P. C.I; CEPIK, C. T.C.; LEVIEN, R.; LOPES, M. T.; BAGGIO, C.; LANG, C. R; SULC, R. M.; PELISSARI, A. O estado da arte em integração lavoura-pecuária. In: GOTTSCHALL, C. S.; SILVA, J. L. S.; RODRIGUES, N. C. (Org.). Produção animal: mitos, pesquisa e adoção de tecnologia. Canoas, 2005. p.7-44.

DECHEN, S. C. F.; TELLES, T.S.; GUIMARÃES, M.F.; DE MARIA, I.C. Perdas e custos associados à erosão hídrica em função de taxas de cobertura do solo. Bragantia, v. 74, n. 2, p. 224-233, 2015. https://doi.org/10.1590/1678-4499.0363

EMBRAPA. Centro Nacional de Pesquisas de Solos. Manual de métodos de análise de solos. 2. ed. Rio de Janeiro: EMBRAPA, 1997. 212 p.

EMBRAPA. Centro Nacional de Pesquisas de Solos. Sistema Brasileiro de Classificação de Solos. 4. ed. Brasília: Embrapa Produção de Informação, 2018. 317 p. 
FACHIN, P. A,; PEREIRA, A. A.; THOMAZ, E. L. Erosão por salpico: padrões de chuva e produção de sedimentos em Latossolo Bruno. Acta Geográfica, v. 13, n. 32, p. 59-75, 2019.

FARZAMIAN, M.; PAZ, M. C.; PAZ, A. M.; CASTANHEIRA, N. L.; GONÇALVES, M. C.; SANTOS, F. A. M.; TRIANTAFILIS, J. Mapping soil salinity using electromagnetic conductivityimaging $-\mathrm{A}$ comparison of regional and location-specificcalibrations. Land Degradation \& Development, v. 30, n. 1, p. 1393-1406, 2019. https://doi.org/10.1002/ldr.3317

FERREIRA, D. F. Sisvar: a guide for its bootstrap procedures in multiple comparisons. Ciência e Agrotecnologia, v. 38, n. 2, p. 109-112, 2014. https://doi.org/10.1590/S1413$\underline{70542014000200001}$

FINNEY, D. M.; KAYE, J. P. Functional diversity in cover crop polyculturesincreases multifunctionality of an agricultural system. Journal of Applied Ecology, v. 54, p. 509-517, 2017. https://doi.org/10.1111/1365-2664.12765

GLÉRIA, A.A.; SILVA, R.M.; SANTOS, A.P.P.; SANTOS, K.J.G.; PAIM, T.P. Produção de bovinos de corte em sistemas de integração lavoura pecuária. Archivos de Zootecnia, v. 66 , n. 253, p.141-150,

2017.

https://doi.org/10.21071/az.v66i253.2138

KLUTHCOUSKI, J.; AIDAR, H. Implantação, condução e resultados obtidos com o sistema Santa Fé. In: KLUTHCOUSKI, J.; STONE, L.F.; AIDAR, H. (Ed.). Integração lavoura-pecuária. Santo Antônio de Goiás: Embrapa Arroz e Feijão, 2003. part. 3, cap.1 5, p. 407-441.

LEMOS, A.M.; CASSOL, E. A.; BARROS, C. A. P. Losses of water, soil, and nutrients during highintensity simulated rainfall in two soil management systems different sources of fertilization. Ciência Rural, v. 50, n. 10, p. 1-11, $2020 . \quad$ https://doi.org/10.1590/0103$\underline{8478 \mathrm{cr} 20190306}$

LIMA, C.A.S. Avaliação do programa de monitoramento ambiental de empreendimentos aquícolas no Estado do Amazonas, Brasil. Revista Colombiana Ciência Animal RECIA, v. 11, n. 2, p. 1-13, 2019. https://doi.org/10.24188/recia.v11.n2.2019.713
LIMA, C. A.; MONTENEGRO, A. A. S.; LIMA, J. L. M. P.; ALMEIDA, T. A. B.; SANTOS, J. C. N. Uso de coberturas alternativas do solo para o controle das perdas de solo em regiões semiáridas. Engenharia Sanitária e Ambiental, v. 25, n. 3, p. 531-542, 2020. https://doi.org/10.1590/s141341522020193900

MARQUES, J. R. A.; NUNES-GUTJAHR, A. L.; BRAGA, E. L. S. Situação sanitária e o uso da água do Igarapé Santa Cruz, município de Breves, Arquipélago de Marajó, Pará, Brasil. Engenharia Sanitária e Ambiental, v. 25, n. 4, p. 597-606, $2020 . \quad$ https://doi.org/10.1590/s141341522020193204

MEDICA, J. A. S.; REIS, N. S.; SANTOS, M. E. R. Caracterização morfológica em pastos de capimmarandu submetidos a frequências de desfolhação e níveis de adubação. Ciência Animal Brasileira, v. 18, n. 1, p. 1-13, 2017. https://doi.org/10.1590/1089-6891v18e-40460

MELO, M. L. A.; BATISTA, A. M.; ARAÚJO, G. S. S.; SILVA, B. M.; VIANA, M. C. M. Estabilidade de agregados em solo cultivado com capim-tifton 85 sob irrigação e formas de suprimento de nitrogênio. Enciclopédia Biosfera, v. 14, n. 25, p. 530-543, 2017.

https://doi.org/10.18677/EnciBio 2017A48

MESTRINHO, S. S. P. Qualidade e classificação das águas subterrâneas. In: GIAMPÁ, C.E.Q.; GONÇALES, V.G. (Org.). Águas subterrâneas e poços tubulares profundos. 2. ed. São Paulo: Oficina de Textos, 2013. Cap. 14. p. 18-496.

NACHTIGALL, S. D.; NUNES, M. C. M.; MOURABUENO, J. M.; LIMA, C. L. R.; MIGUEL, P.; BESKOW, S.; SILVA, T. P. Modelagem espacial da erosão hídrica do solo associada à sazonalidade agroclimática na região sul do Rio Grande do Sul, Brasil. Engenharia Sanitaria e Ambiental, v. 25, n. 6, p. 933-946, 2020. https://doi.org/10.1590/s1413$\underline{4152202020190136}$

NEVES, R. C.; VILAR, C. C.; USHIWATA, S. Y.; COSTA, A. C.; HARTWIG, C. F. V.; CHAVES, J. S. Persistência de palhada de Urochloa ruziziensis em sistema de plantio direto e convencional no município de Nova Xavantina-MT. Global Science and Technology, v. 11, n. 03, p. 110-122, 2018. 
https://rv.ifgoiano.edu.br/periodicos/index.php/ gst/article/view/1030/623

PANACHUKI, E.; BERTOL, I.; SOBRINHO, T. A.; OLIVEIRA, P. T. S.; RODRIGUES, D. B. B. Perdas de solo e de água e infiltração de água em latossolo vermelho sob sistemas de manejo. Revista Brasileira de Ciência do Solo, v. 35, n. 5, p. 17771785, 2011. https://doi.org/10.1590/S0100$\underline{06832011000500032}$

PARIZ, C. M.; ANDREOTTI, M.; BUZETTI, S.; BERGAMASCHINE, F. A.; ULIAN, N. A.; FURLAN, L. C.; MEIRELLES, P. R. L.; CAVASANO, F. A. Straw decomposition of nitrogen-fertilized grasses intercropped with irrigated maize in an integrated crop livestock system. Revista Brasileira de Ciência do Solo, v. 35, n. 6, p. 0292037, 2011. https://doi.org/10.1590/S0100$\underline{06832011000600019}$

PIRES, L. S.; BRITO, L .F.; SILVA, M. L. N.; CURI, N.; LEITE, F. P.; BRITO, L. F. Erosão hídrica pós-plantio em florestas de eucalipto na região centro-leste de Minas Gerais. Pesquisa Agropecuária Brasileira, v. 41, p. 687-695, 2006. https://doi.org/10.1590/s0100-

204X2006000400021.

PRAZERES, M. S.; OLIVEIRA, G. F.; SILVA, A. L. P.; ROTERS, D. F.; SANTOS, V. P.; BERTOL, I. Chuva simulada: avaliação de perdas de solo e água em um cambissolo húmico. Ciencia Suelo, v. 38 , n. 1, p. $199-202,2020$

SANTOS, I. L.; CAIXETA, C. F.; SOUSA, A. A. T. C.; FIGUEIREDO, C. C.; RAMOS, M. L. G.; CARVALHO, A. M. Cover plants and mineral nitrogen: effects on organic matter fractions in an oxisol under notillage in the cerrado. Revista Brasileira de Ciência do Solo, v. 38, n.6, p. 1874-1881, 2014. https://doi.org/10.1590/S0100-

$\underline{06832014000600022}$

SILVA, D, D.; PRUSKI, F, F.; SCHAEFER, G, E, G, R.; AMORIN, R, S, S.; PAIVA, K, W, N. Efeito da cobertura nas perdas de solo em um argissolo vermelho amarelo utilizando simulador de chuva. Engenharia Agrícola, v. 25, n. 2, p. 409-419, 2005. https://doi.org/10.1590/S0100$\underline{69162005000200014}$

VIEL, J. A.; ROSA, S. S.; HOFF, R. Estudo da erosão superficial do solo por meio de SIG na região da denominação de origem Vale dos Vinhedos (Brasil). Revista Brasileira de Geomorfologia, v. 18 , n. 13, p. 521-533, 2017. https://doi.org/10.20502/rbg.v18i3.1197

ZANGISKI, F.; MIQUELLUTI, D. J.; BERTOL, I.; RAMOS, J. C. Soil roughness indexes and their relationship with water erosion. Pesquisa Agropecuária Brasileira, v. 53, n. 6, p. 756-764, $2018 . \quad$ https://doi.org/10.1590/s0100$\underline{204 \times 2018000600012}$

ZOLIN, C. A.; PAULINO, J.; MATOS, E. S.; MAGALHAES, C. A. S.; ALMEIDA, F. T.; SOUZA, A. P.; MINGOTI, R. Perda de solo e água sob integração lavoura-floresta e em sucessão sojamilho. Pesquisa Agropecuária Brasileira, v. 51, n. 9, p. 1223-1230, 2016. https://doi.org/10.1590/s0100204×2016000900022. 